\title{
EFEITO DA SALINIDADE NA GERMINAÇÃO DE PEPINO
}

\author{
Gustavo Teodoro Rocha ${ }^{1}$, Guilherme Teodoro Rocha ${ }^{1}$, Gabriela Teodoro Rocha²
}

\begin{abstract}
RESUMO - Os estudos relacionados com a germinação de sementes submetidas a estresses artificiais têm importância essencial para a ecofisiologia e constituem-se em mecanismos que possibilitam a avaliação dos limites de tolerância e adaptação destas espécies às condições de estresses naturais. O objetivo deste trabalho foi avaliar o potencial germinativo de diferentes cultivares de sementes de pepino submetidos ao estresse salino provocado pelo cloreto de potássio. O delineamento experimental utilizado foi inteiramente casualizado, com quatro repetições contendo cinquenta sementes por repetição, submetidas a germinação, em condições de estresse salino sob cinco níveis $(0 ;-0,2 ;-0,4 ;-0,6 ;-0,8) \mathrm{MPa}$, simulados com soluções de cloreto de potássio. As variáveis avaliadas foram porcentagem de germinação, índice de velocidade de germinação e o tempo médio de germinação. Se tratando de tolerância ao estresse salino, as cultivares Aodai da Topseed ${ }^{\circledR}$ e Safira da Sakata ${ }^{\circledR}$ se sobressaíram sobre a cultivar Colonião branco. Conclui-se que a diminuição progressiva do potencial osmótico é prejudicial as três cultivares de pepino.
\end{abstract}

Palavras chave: Cucumis sativus L., potencial osmótico, solo salino.

\section{EFFECT OF SALINITY IN THE GERMINATION OF Cucumber}

\begin{abstract}
Studies related to the germination of seeds submitted to artificial stresses are essential for the ecophysiology and constitute mechanisms that allow the evaluation of the limits of tolerance and adaptation of these species to natural stress conditions. The objective of this work was to evaluate the germinative potential of different cultivars of cucumber seeds submitted to salt stress caused by potassium chloride $(\mathrm{KCl})$. The experimental design was completely randomized, with four replicates containing fifty seeds per replicate, submitted to germination under saline stress conditions under five levels $(0,-0.2,-0.4,-0.6,-0,8)$ of osmotic potential, simulated with solutions of potassium chloride (KCL). The variables were percentage of germination (GERM), germination speed index (IVG) and mean germination time (TMG). In the case of tolerance to saline stress, the Topayed ${ }^{\circledR}$ and Sapata sapphire aodai cultivars excelled on the white colonized cultivar. Concluded that the progressive decrease of the osmotic potential of $\mathrm{KCl}$ is detrimental to the three cucumber cultivars.
\end{abstract}

Keywords: Cucumis sativus L., saline soil, osmotic potential.

\section{INTRODUÇÃO}

O pepino (Cucumis sativus L.) é uma hortaliça pertencente à família das Curcubitaceaes, com seu centro de origem da Índia, sendo posteriormente disperso para a China, Filipinas e Ilhas Formosas (Medeiros et al., 2010).

A cultura destaca-se no comércio brasileiro, em relação as demais hortaliças, devido a sua elevada apreciação como componente de saladas, sanduíches, sopas e conservas. Além disto, pode ser utilizado em cosméticos e medicamentos devido a suas propriedades nutracêuticas (Embrapa, 2013; Silva et al., 2014).

É uma espécie de clima quente, o qual adapta-se a temperaturas amenas, principalmente se cultivadas em ambiente protegido (Filgueira, 2013). A produção média mundial do pepino caracteriza-se por $200.000 \mathrm{t} \mathrm{ha}^{-1}$, sendo

\footnotetext{
${ }^{1}$ Engenheiros-Agrônomos - Universidade Estadual de Goiás (UEG), Campus Ipameri, Goiás, gutto_teodoro@hotmail.com e guilherme_ocha@hotmail.com.

${ }^{2}$ Doutoranda em Agronomia - Universidade de Brasília (UnB), Brasília, Distrito Federal, gabriela_teodoro.rocha@yahoo.com.br
} 
a China a detentora de $60 \%$ da produção. Os principais grupos de pepinos cultivados no Brasil são o Aodai, Caipira e Japonês, no qual 50\% da produção média anual dos frutos são produzidos nas regiões do Sudeste e Nordeste do país (Filgueira, 2008; Agrianual, 2010; Carvalho et al., 2013).

No entanto, a produção do pepino, principalmente na região nordeste, se predispõe a clima semiárido, caracterizado por baixas precipitações pluviométricas, e águas disponíveis para irrigação contendo altos índices salinos (Medeiros et al., 2003). A salinidade do solo e da água é um dos principais fatores de estresse abiótico que afetam os diversos aspectos da fisiologia e morfologia das plantas em sua germinação e o desenvolvimento (Deuner et al., 2011; Maia et al., 2012).

Sob condições salinas a espécie tende a ter uma redução na absorção de água pela semente em função do efeito dos íons, o qual causam distúrbios nos processos de germeabilidade de suas plântulas. Porém o grau de dano apresentado pela planta é dependente da tolerância da espécie à salinidade (Munns, 2005; Nobre et al., 2013).

Ao reduzir a absorção e o transporte de água nas sementes há também a diminuição de nutrientes essências as plantas acarretando um desequilíbrio nutricional na espécie originando alterações nas estruturas da membrana e inibindo diversas atividades enzimáticas no metabolismo da cultura (Aragão et al., 2010). O acúmulo de KCL pode acarretar o rompimento das camadas tegumentares e causar agravos ao embrião, podendo levar a morte das sementes ou a má formação da mesma prejudicando a produtividade da espécie em campo (Freitas et al., 2013).

O comportamento de plantas quando expostas a estresses salinos, objetivando maior produtividade e tolerância dessas espécies às condições ambientais desfavoráveis está sendo cada vez mais estudado. Diante disto, o objetivo deste trabalho foi avaliar o potencial germinativo de diferentes cultivares de sementes de pepino submetidos ao estresse salino provocado pelo cloreto de potássio $(\mathrm{KCl})$.

\section{MATERIAL E MÉTODOS}

O experimento foi realizado no Laboratório Multidisciplinar da Universidade de Goiás, no Campus Ipameri (Latitude $17^{0} 43^{\prime} \mathrm{S}$, Longitude $48^{\circ} 08^{\prime} \mathrm{N}$ ), a 790 $\mathrm{m}$ de altitude, no período de 06/04/2017 a 14/04/2017. Para o ensaio experimental foram selecionadas sementes de três cultivares de pepino (Cucumis sativus L.), sendo a cultivar caipira (Colonião branco), adquirida da coleção pessoal da Universidade Estadual de Goiás, E as cultivares hibridas Safira - Sakata ${ }^{\circledR}$ e a espécie hibrida japonesa Aodai - Topseed $^{\circledR}$.

As sementes de Colonião branco foram desinfestadas em hipoclorito de sódio a $2 \%$, por 1 minuto, seguidas por lavagem em água corrente, afim de eliminar qualquer contaminante presente nas sementes. Entretanto para as outras cultivares não houve a necessidade de serem desinfestadas, uma vez que foram adquiridas de um lote previamente esterilizado.

Utilizou-se o delineamento experimental inteiramente casualizado, com quatro repetições, contendo 50 sementes por repetição. A semeadura foi realizada em papel germitest umedecido com as soluções salinas em quantidade equivalente a 2,5 vezes o seu peso. Após realizada a semeadura das sementes, os rolos de papeis foram embalados em sacos plásticos, para manter umidade, e alocados em BOD (Biochemical Oxygen Demand) a $25^{\circ} \mathrm{C}$.

Para as soluções salinas estabeleceu-se os potenciais osmóticos $0 ;-0,2 ;-0,4 ;-0,6$ e - $0,8 \mathrm{MPa}$, obtidos com soluções aquosas de $\mathrm{KCl}$, apresentando os seguintes valores de condutividade elétrica (CE): 0,0 (água destilada); 5,$6 ; 11,2 ; 16,7 ; 22,3 \mathrm{dSm}^{-1}$.

As concentrações foram calculadas pela equação de Van't Hoff, citado por Salysbury e Ross (1992): $\Psi 0$ s = RTC, sendo: Yos: potencial osmótico (atm); R: constante geral dos gases perfeitos $\left(0,082\right.$ atm $\left.\mathrm{L} \mathrm{mol}^{-1}{ }^{\circ} \mathrm{K}^{-1}\right)$; $\mathrm{T}$ : temperatura $\left({ }^{\circ} \mathrm{K}\right)$ e $\mathrm{C}$ : concentração $\left(\mathrm{mol} \mathrm{L}^{-1}\right)$.

Foram realizadas avaliações de porcentagem de Germinação (GERM), determinada pela fórmula proposta pelas Regras para Análise de Sementes (Brasil, 1992); seguindo as equações $\mathbf{G}=\mathbf{N G} \times \mathbf{1 0 0} / \mathbf{N T}$, sendo: $\mathrm{NG}=$ número de sementes germinadas; e $\mathrm{NT}=$ número de sementes colocadas para germinar.

O Índice de Velocidade de Germinação (IVG), calculado pela fórmula proposta por Maguire (1962): IVG: $\left(\mathbf{G}_{\mathbf{1}} / \mathbf{N}\right)+\left(\mathbf{G}_{\mathbf{2}} / \mathbf{N}\right)+\left(\mathbf{G}_{\mathbf{n}} / \mathbf{N}_{\mathbf{n}}\right)-$ sendo: $\mathrm{G}_{1}, \mathrm{G}_{2}$ e $\mathrm{G}_{\mathrm{n}}=$ número de plântulas normais computadas na primeira, na segunda e na última contagem; e $\mathrm{N}_{1}, \mathrm{~N}_{2}$ e $\mathrm{N}_{\mathrm{n}}=$ número de dias da semeadura à primeira, segunda e última contagem. E o Tempo Médio de Germinação (TMG), calculado pela equação proposta por Ferreira (2008): $\mathbf{t}=\Sigma \mathbf{n}_{\mathrm{i}} \cdot \mathbf{t} / \Sigma \mathbf{n}_{\mathrm{i},}$ sendo: $\mathrm{ni}$ é o número de sementes germinadas dentro de determinado intervalo de tempo $t_{i}^{-1}$ e $t_{i}$.

Foram feitas avalições de comprimento da Parte Aérea (CPA) e o comprimento da parte radicular (CPR) no 
oitavo dia após a semeadura. Foram selecionadas ao acaso 25 plântulas, que posteriormente foram aferidas com o auxílio de uma régua graduada em $\mathrm{cm}$, o comprimento da parte aérea (hipocótilo) e radicular (radícula), obtendo-se uma média para cada tratamento.

Os dados foram transformados em raiz quadrada $(x+0,5)^{\wedge} 0,5$, uma vez que não apresentaram variâncias homogêneas pelo teste de Shapiro Wilk. Posteriormente eles foram submetidos à análise de variância pelo teste de $\mathrm{F}$ e as médias comparadas pelo teste de Scott Knott a 5\% de probabilidade utilizando o programa SISVAR 5.0 (Ferreira, 2011).

\section{RESULTADOS E DISCUSSÃO}

Observa-se na Tabela 1, que houve influência significativa $(\mathrm{p}<0,05)$ da interação salinidade e cultivares de pepino para as variáveis de GERM, IVG, TMG, CPA e CPR. Contudo, ressalva-se que apenas o TMG, avaliado na cultivar Aodai, não apresentou significância.

O efeito significativo da salinidade sob a germinação de cucurbitáceas também foram constatados por Albuquerque et al. (2016) em cultivares de pepino Aodai e Wisconsin SEM-58; em melão pepino por Nóbrega et al. (2018); em cultivares de melancia (Martins et al., 2013).

Tabela 1 - Quadrado médio para as variáveis de porcentagem de germinação (GERM), índice de velocidade de germinação (IVG), tempo médio de germinação (TMG), comprimento da parte aérea (CPA) e comprimento da parte radicular (CPR), submetidos a diferentes potenciais osmóticos de $\mathrm{KCl}$ em cultivares de Aodai, Colonião branco e Safira.

\begin{tabular}{|c|c|c|c|c|c|c|}
\hline \multicolumn{7}{|c|}{ Aodai } \\
\hline FV & GL & GERM & IVG & TMG & $\mathrm{CPA}$ & CPR \\
\hline Tratamento & 4 & $5,018^{* *}$ & $0,835^{* *}$ & $0,004^{\mathrm{ns}}$ & $41,026^{* *}$ & $80,990^{* *}$ \\
\hline Repetição & 3 & 0,224 & 0,031 & 0,003 & 0,036 & 0,054 \\
\hline erro & 12 & 0,098 & 0,019 & 0,001 & 0,102 & 0,129 \\
\hline CV $(\%)$ & & 3,59 & 3,91 & 2,29 & 19,94 & 17,22 \\
\hline \multicolumn{7}{|c|}{ Colonião branco } \\
\hline FV & GL & GERM & IVG & TMG & CPA & CPR \\
\hline Tratamento & 4 & $2614,80^{* *}$ & $79,568^{* *}$ & $1,300^{* *}$ & $82,096^{* *}$ & $79,083^{* *}$ \\
\hline Repetição & 3 & 82,666 & 2,096 & 0,043 & 1,084 & 0,410 \\
\hline erro & 12 & 87,333 & 2,217 & 0,070 & 0,175 & 0,211 \\
\hline CV $(\%)$ & & 15,79 & 16,03 & 7,51 & 23,93 & 22,22 \\
\hline \multicolumn{7}{|c|}{ Safira } \\
\hline $\mathrm{FV}$ & GL & GERM & IVG & TMG & CPA & CPR \\
\hline Tratamento & 4 & $5,830^{* *}$ & $1,282^{* *}$ & $0,024^{* *}$ & $66,391^{* *}$ & $74,319^{* *}$ \\
\hline Repetição & 3 & 0,479 & 0,061 & 0,000 & 2,101 & 1,197 \\
\hline erro & 12 & 0,716 & 0,105 & 0,000 & 0,132 & 0,143 \\
\hline CV (\%) & & 9,11 & 8,60 & 1,35 & 19,84 & 18,89 \\
\hline
\end{tabular}

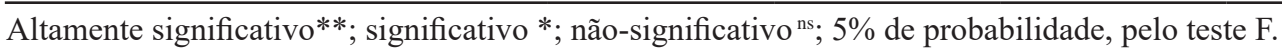

Verifica-se na Figura $1 \mathrm{~A}$, que o percentual germinativo das sementes de pepino Colonião branco, Aodai e Safira apresentaram declínio de 43,7\%, 20\% e 15\% respectivamente, sob concentrações salinas de -0,8 Mpa. Estes resultados indicam que a germinação das sementes é dependente de potenciais osmóticos próximos ao nulo, ao qual constata-se que concentrações a partir -0,4 Mpa são aceitáveis para o desenvolvimento das cultivares.

Marcos-Filho (2005) \& Matias et al. (2015), explicam que estresse abiótico prejudica o crescimento 
do eixo embrionário, assim como as rotas fisiológicas e bioquímicas responsáveis por desencadear o processo germinativo nas sementes, reduzindo assim a porcentagem de germinação nas plantas.

Resultados semelhantes foram verificados por Torres et al. (2000), ao qual constaram que potenciais osmóticos de $\mathrm{KCl}$ superiores a $-0,4 \mathrm{MPa}$ proporcionaram reduções significativas no desempenho germinativo de cultivares de pepino, verificando uma redução percentual de $36 \%$ na germinação da espécie sobre a concentração de -0,8 Mpa. Entretanto, Matias et al. (2015) constatou que a cultivar de pepino Caipira, com substratos irrigados com solução salina, com $\mathrm{KCl}$ obteve resultados semelhantes de germinação em todos os tratamentos.
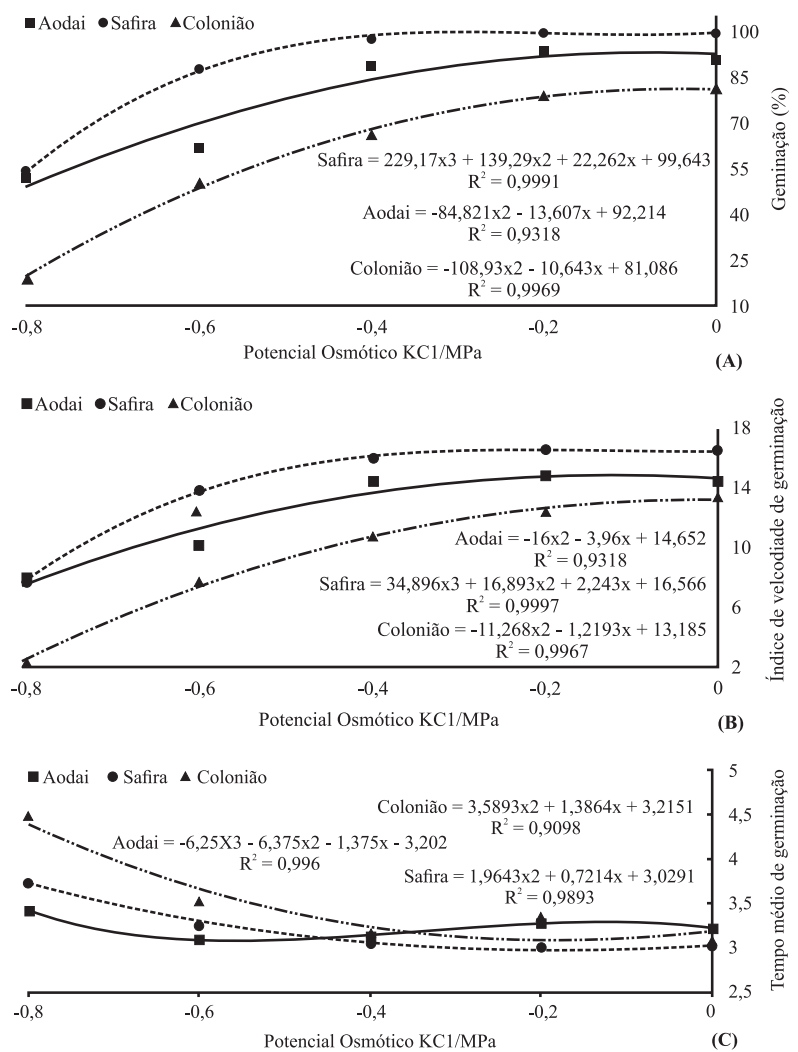

Figura 1 - Modelos de regressão para germinação (1A), índice de velocidade de germinação (1B) e tempo médio de germinação (1C) em função das diferentes concentrações de cloreto de potássio $(\mathrm{KCl})$.

$\mathrm{Na}$ análise de IVG (Figura 1B), os resultados obtidos demonstram uma curva quadrática decrescente para as três cultivares testadas, apresentando influência negativa a partir de $-0,4 \mathrm{Mpa}$. Com relação a tolerância à salinidade, a cultivar Colonião branco apresentou resultados inferiores em comparação as outras cultivares de pepino Aodai e Safira, sendo estas diferenças apresentada por 2 e 3 plântulas - dias (controle); 2 e 4 (-0,2 Mpa); 4 e 6 (0,4 Mpa); 3 e $6(0,6 \mathrm{Mpa})$ e 6 e 5 plântulas-dias ( $0,8 \mathrm{Mpa})$, indicando maior susceptibilidade ao estresse salino.

Semelhantes a estes resultados foram obtidos por Carvalho \& Kazama (2011) em sementes de pepino sob as mesmas concentrações osmóticas, aos quais verificaram que o IVG apresentou sensibilidade ao aumento das concentrações de $\mathrm{KCl}$ reduzindo a formação de plântulas por dia.

De acordo com PEREZ et al. (2001), o retardamento na velocidade de germinação das plantas é explicado pelo aumento no potencial osmótico salino sobre as fases de embebição das sementes, no qual a primeira fase caracteriza-se pela redução no gradiente de absorção de água das sementes. Consequentemente ocorre a ativação do metabolismo germinativo da espécie, elevando o teor relativo de água na semente, assim iniciando a segunda fase de embebição. Porém, na terceira fase, a absorção de água se associa ao crescimento e à emergência da radícula, no qual as soluções salinas interferem na entrada de água, restringindo assim a absorção de água na planta e reduzindo a taxa de crescimento da radícula, ocasionado maior tempo em sua formação.

Na Figura 1C verifica-se que a salinidade reduziu o potencial osmótico do meio, ao passo que prolongou o tempo necessário para a absorção de água pelas sementes e consequentemente o período de germinação e crescimento das plântulas. As cultivares Aodai e Safira apresentaram um TMG de 3 a 4 dias, sendo o maior período de germinação decorrente ao aumento da salinidade com $\mathrm{KCl}$, contudo, o TMG da cultivar Colonião branco obteve resultados inferiores, sendo uma diferença de um dia de crescimento.

Segundo Ferreira et al. (2001), o TMG é importante para avaliar a rapidez de ocupação de uma espécie em uma comunidade. O alto valor de TMG é explicado por Silva et al. (2000), o qual relata que em meio salino, o tempo necessário para a absorção de água pelas sementes é prolongado, devido a redução do potencial osmótico do meio ou pelo efeito fitotóxico dos sais sobre o embrião das sementes. Este fato foi observado nas cultivares de pepino, uma vez que em altas concentrações salinas as sementes da espécie necessitaram de um período de germinação relativamente maior que as sementes embebidas em água (controle). 
O estresse salino influenciou drasticamente a cultivar colonião tanto para comprimento da parte aérea (CPA) quanto para comprimento da parte radicular (CPR), verificando uma redução de aproximadamente $100 \%$ do controle a concentração de $-0,8 \mathrm{Mpa}$ (Figura 2).

As cultivares Safira e Aodai demonstraram uma curva cúbica na Figura 2, constando resultados próximos de 6 e $5 \mathrm{~cm}$ de CPA e CPR no tratamento controle (água) e na concentração de $-0,2 \mathrm{MPa}$ respectivamente. Porém ao serem submetidas a condições salinas elevadas observouse decréscimos de $77 \%$ e $95 \%$ com relação a concentração de -0,8 Mpa. Guimarães et al. (2008) verificaram respostas negativas para altura em maxixe devido aos efeitos da salinidade, o qual encontraram uma variação de 2,15 a 7,6 $\mathrm{cm}$, para as salinidades 0,5 e $6,5 \mathrm{dS} \mathrm{m}^{-1}$, respectivamente obtendo uma redução de $64,6 \%$ da maior concentração para a testemunha (água).

Os aumentos no teor de sais no substrato provocam redução do potencial hídrico, induzindo menor capacidade de absorção de água pelas sementes, com influência direta na germinação e no desenvolvimento das plântulas (Rebouças et al., 1989).

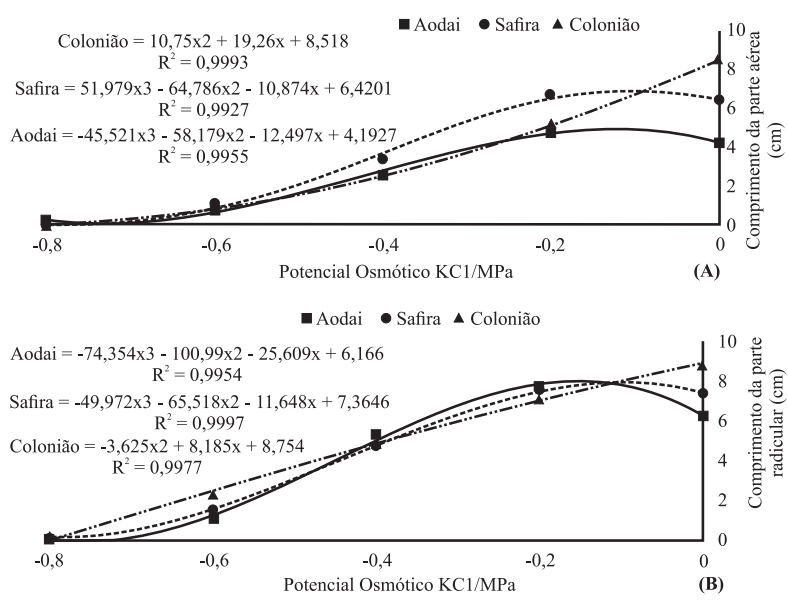

Figura 2 - Modelos de regressão para Comprimento da parte aérea (2A) e Comprimento da parte radicular (2B) em função das diferentes concentrações de cloreto de potássio $(\mathrm{KCl})$.

\section{CONCLUSÃO}

A diminuição progressiva do potencial osmótico de $\mathrm{KCl}$ é prejudicial as três cultivares de pepino, principalmente sobre altas concentrações osmóticas $(-0,8$ Mpa).
Se tratando de tolerância ao estresse salino, as cultivares apresentaram resultandos semelhantes entre si, contudo as cultivares Aodai da Topseed ${ }^{\circledR}$ e Safira da Sakata ${ }^{\circledR}$ se sobressaíram sobre a cultivar Colonião branco nos quesitos de germinação e crescimento das plântulas.

\section{LITERATURA CITADA}

AGRIANUAL 2010: Anuário estatístico da agricultura brasileira. São Paulo: Argos Comunicação, 2009. 520 p.

ALBUQUERQUE, J. R. T.; SÁ, F. V. S.; OLIVEIRA, F. A.; PAIVA, E. P.; ARAÚJO, E. B. G.; SOUTO, L. S. Crescimento inicial e tolerância de cultivares de pepino sob estresse salino. Revista Brasileira de Agricultura Irrigada-RBAI, v. 10, n. 2, p. 486-495, 2016.

ARAGÃO, R. M.; SILVEIRA, J. A. G.; SILVA, E. N.; LOBO, A. K. M.; DUTRA, A. T. B. Absorção, fluxo no xilema e assimilação do nitrato em feijão-caupi submetido à salinidade. Revista Ciência Agronômica, v. 41, n. 1, p. 100-106, 2010.

BRASIL, Ministério da Agricultura e Reforma Agrária, Coordenação de Laboratório Vegetal. Regras para análise de sementes. Brasília: 2009. 399 p.

CARVALHO, A. D. F.; AMARO, G. B.; LOPES, J. F.; VILELA, N. J.; MICHEREFF FILHO, M.; ANDRADE, R. A cultura do pepino. Circular técnica - Ministério da Agricultura, Pecuária e Abastecimento, $n^{\circ}$ 113, pg 1-18, 2013.

CARVALHO, L.C; KAZAMA, E.H. Efeito da salinidade de cloreto de potássio $(\mathrm{KCl})$ na germinação de sementes e crescimento de plântulas de pepino (cucumis sativus l.). Enciclopédia Biosfera, Centro Científico Conhecer, Goiânia, v.7, n. 13; pg. 429-435, 2011.

DEUNER, C.; MAIA, M. S.; DEUNER, S.; ALMEIDA, A. S.; MENEGHELLO, G. E Viabilidade e atividade antioxidante de sementes de genótipos de feijão-miúdo submetidos ao estresse salino. Revista Brasileira de Sementes, Londrina, v. 33, n .4, p. 711-720, 2011.

FERREIRA, A. G.; CASSOL, B.; ROSA, S. G. T.; SILVEIRA, T. S.; STIVAL, A. L.; SILVA, A. A. Germinação de sementes de Asteraceae nativas no Rio Grande do Sul, Brasil. Acta Botanica Brasilica, São Paulo, v. 15, n. 2, p. 231-242, 2001.

FERREIRA, Al. G.; BORGUETTI, F. Germinação: do básico ao aplicado. Artmed, 2008.

FERREIRA, D. F. Sisvar: a computer statistical analysis system. Ciência e Agrotecnologia, v. 35, n. 6, p. 1039-1042, 2011. 
FERREIRA, P. A. Aspectos físico-químicos do solo. In: GHEI, H. R.; QUEIROZ, J. E.; MEDEIROS, J. F. Manejo e controle da salinidade na agricultura irrigada. Campina Grande: UFPB/SBEA, 1997. p. 37-67.

FILGUEIRA, F. A. R. Novo manual de olericultura: agrotecnologia moderna na produção e comercialização de hortaliças. 3. ed. Viçosa: UFV, 2013. 421 p.

FREITAS, A. R.; LOPES, J. C.; MATHEUS, M. T.; MENGARDA, L. H. G.; VENANCIO, L. P. CALDEIRA, M. V. W. Superação da dormência de sementes de jatobá. Pesquisa Florestal Brasileira, Colombo, v. 33, n. 73, p. 01-05, 2013.

GÓIS, V.A; TORRES, S.B.; PEREIRA, R. A. Germinação de sementes de maxixe submetidas a estresse salino. Revista Caatinga, v. 21, n. 4, 2008.

GUIMARÃES, I. P.; OLIVEIRA, F. A.; FREITAS, A. V. L.; MEDEIROS, M. A.; OLIVEIRA, M. K. T. Germinação e vigor de sementes de maxixe irrigado com água salina. Revista Verde, Mossoró, v.3, n.2, p. 50-55, 2008.

MAGUIRE, J.D. Speed of germination and in selection and evaluation for seedling emergence and vigor. Crop Science, Madison, v.2, p.176-177, 1962.

MARTINS, D. C.; RIBEIRO, M. S. S.; SOUZA NETA, M. L.; SILVA, R. T.; GOMES, L. P.; GUEDES, R. A. A.; OLIVEIRA, F.A. Tolerância de cultivares da melancia à salinidade da água de irrigação. Agropecuária Científica no Semiárido, v. 8, n. 3, p. 62-68, 2013.

MATIAS, J. R.; BRITO, I. A.; GOMES, S. E. V.; DA COSTA, D. C. C.; DE OLIVEIRA, G. M.; DOS SANTOS, J. B.; DANTAS, B. F. Germinação de sementes de catingueiracerdadeira (Poincianella pyramidalis Tul.) em condições de restrição hídrica. In: Embrapa Semiárido-Artigo em anais de congresso (ALICE). In: SIMPÓSIO DE MUDANÇAS CLIMÁTICAS E DESERTIFICAÇÃO NO SEMIÁRIDO BRASILEIRO, Petrolina. Experiências e oportunidades para o desenvolvimento. Petrolina: Embrapa Semiárido, 2015.

MARCOS FILHO, J. Fisiologia de sementes de plantas cultivadas. Piracicaba: Fealq, 2005. 495 p.

MATIAS, J. R.; SILVA, T. C. F.; OLIVEIRA, G. M.; ARAGÃO, C. A.; DANTAS, B. F. Germinação de sementes de pepino cv. Caipira em condições de estresse hídrico e salino. Revista Sodebras, v. 10, n. 113, p. 33-39, 2015.

MEDEIROS, J. F. DE; LISBOA, R. DE A.; OLIVEIRA, M. DE; SILVA JÚNIOR, M. J. DA; ALVES, L. P. Caracterização das águas subterrâneas usadas para irrigação na área produtora de melão da Chapada do Apodi. Revista Brasileira Engenharia Agrícola e Ambiental, v. 7, n. 3, p. 469-472, 2003.

MEDEIROS, P. R. F.; DUARTE, S. N.; DIAS, C. T. S.; SILVA, M. F. D. Tolerância do pepino à salinidade em ambiente protegido: Efeitos sobre propriedades físico-químicas dos frutos. Irriga, n.3, p.301-311, 2010.

MEDEIROS, P. R. F.; DUARTES, S. N.; DIAS, C. T.S. Tolerância da cultura do pepino à salinidade em ambiente protegido. Revista Brasileira de Engenharia Agrícola e Ambiental. Campina Grande, PB v.13, n.4, p.406-410, 2009.

NOBRE, R. G.; LIMA, G. S.; GHEYI, H. R.; LOURENÇO, G. S.; SOARES, L. A. S. Emergência, crescimento e produção da mamoneira sob estresse salino e adubação nitrogenada. Revista Ciência Agronômica, v. 44, n. 1, p. 76-85, 2013.

NÓBREGA, J. S.; FIGUEIREDO; F. R. A.; NASCIMENTO, R. G. S.; BRUNO, R. D. L.A.;ALVES, E. U.; CAVALCANTE, L. F. Qualidade fisiológica de sementes de melão pepino sob salinidade crescente da água de irrigação. Revista de Ciências Agrárias, v. 41, n. 4, p. 141-150, 2018.

PEREZ, S. C. J. G. A., FANTI, S. C., CASAli, C. A. Influência da luz na germinação de sementes de Canafístula submetidas ao estresse hídrico. Bragantia, Campinas, v. 60, n. 3, p. 155-166, 2001.

REBOUÇAS, M. A.; FAÇANHA, J. G. V.; FERREIRA, L. G. R \& PRISCO, J. T. Crescimento e conteúdo de N, P, K e $\mathrm{Na}$ em três cultivares de algodão sob condições de estresse salino. Revista Brasileira de Fisiologia Vegetal, Brasília, v.1, n.1, p.79-85, 1989.

SILVA, E. F.; SOUZA, E. G. F.; SANTOS, M. G.; ALVES, M. J. G.; BARROS JÚNIOR, A. P.; SILVEIRA, L. M.; SOUSA, T. P. Qualidade de mudas de pepino produzidas em substratos à base de esterco ovino. Agropecuária Cientifica no Semiárido, v.10, n.3, p.93-99, 2014.

SILVA, F.A.M.; MELLONI, R.; MIRANDA, J.R.P.; CARVALHO, J.G. Efeito do estresse salino sobre a nutrição mineral e o crescimento de mudas de aroeira (Myracrodruon Urundeuva) cultivadas em solução nutritiva. Cerne, v.6, n.1, 2000.

TORRES, S. B.; VIEIRA, E. L.; MARCOS-FILHO, J. Efeitos da salinidade na germinação e no desenvolvimento de plântulas de pepino. Revista Brasileira de Sementes, v.22, n.2, p.39-44, 2000.

Recebido para publicação em 18/03/2019 e aprovado em 17/8/2019

Revista Brasileira de Agropecuária Sustentável (RBAS), v.9, n.3, p.42-47, Setembro, 2019 